\title{
Processing modifier-head agreement in reading: Evidence for a delayed effect of agreement
}

\author{
SEPPO VAINIO AND JUKKA HYÖNÄ \\ University of Turku, Turku, Finland \\ AND \\ Anneli Pajunen \\ University of Tampere, Tampere, Finland
}

\begin{abstract}
The present study examined whether type of inflectional case (semantic or grammatical) and phonological and morphological transparency affect the processing of Finnish modifier-head agreement in reading. Readers' eye movement patterns were registered. In Experiment 1, an agreeing modifier condition (agreement was transparent) was compared with a no-modifier condition, and in Experiment 2, similar constructions with opaque agreement were used. In both experiments, agreement was found to affect the processing of the target noun with some delay. In Experiment 3, unmarked and case-marked modifiers were used. The results again demonstrated a delayed agreement effect, ruling out the possibility that the agreement effects observed in Experiments 1 and 2 reflect a mere modifier-presence effect. We concluded that agreement exerts its effect at the level of syntactic integration but not at the level of lexical access.
\end{abstract}

The term agreement designates the phenomenon in which the same grammatical category (or meaning) is formally marked in two or more words of a clause. Or, schematically, $(\mathrm{X}-\mathrm{A})+(\mathrm{Y}-\mathrm{A})$, where $\mathrm{A}$ is the exponent of a category common to both $\mathrm{X}$ and $\mathrm{Y}$. In this way, coherence-both within and between sentence constituents - is explicitly expressed. Considering the central role that agreement plays in the grammatical descriptions of many languages, studying its possible role in online sentence processing is highly warranted and was the main aim of the present study.

Cross linguistically, the most important grammatical categories involved in agreement are number, gender, person, and case. When an agreement construction is represented by $(\mathrm{X}-\mathrm{A})+(\mathrm{Y}-\mathrm{A})$, then the default assumption is that A expresses a single grammatical category - as in Finnish uus-i-ssa talo-i-ssa ("in [the] new houses") where $-i-=$ number (i.e., plural) and $-s s a=$ case (i.e., inessive). However, it is often the case that A simultaneously expresses more than one grammatical categoryas in Spanish las chic-as guap-as ("the beautiful girls"), where las denotes number (i.e., plural), gender (i.e., feminine), and species (i.e., definite) — or as in Finnish lapse-t juokse-vat ("[the] children are running"), where $-t=$ number (i.e., plural) and case (i.e., nominative), - vat $=$ number (i.e., plural) and person (i.e., third). Finally, the exponents of a given grammatical category need not be formally identical. That is, from the purely formal point of view, agreement can also be exemplified by constructions like $(\mathrm{X}-\mathrm{A})+(\mathrm{Y}-\mathrm{B})$
Agreement may appear in many syntactic constructions, such as adjectival modifier-head, possessive modifierhead, adposition-noun, subject-verb, object-verb, subject-predicate nominal, subject/object-participle, and so on. The modifier-head and the subject-verb constructions exemplify agreement within a constituent and between constituents, respectively. In this article, we investigate the reading process as applied to the case and number agreement in Finnish modifier-head constructions. In what follows, unless otherwise specified, the notion of agreement in Finnish will thus be restricted to case and number agreement in modifier-head constructions.

\section{Morphological Features of Finnish}

Next, we summarize relevant morphological features that show that Finnish is a suitable language to study casenumber agreement in modifier-head constructions.

Finnish is a morphologically rich language in which case-number agreement is expressed by means of suffixes. There are two numbers - that is, singular and plural — and 15 cases of which approximately 12 are in productive use. Note that up to $70 \%$ of words in written text are case inflected.

The phrase-level word order is rigid in Finnish, and the (adjectival) modifier always precedes its head noun, without any intervening words. In addition, the modifier strictly agrees with the case and number of its head noun (see Sulkala \& Karjalainen, 1992).

Cases can be placed on a continuum depending on whether the relations they express are concrete or abstract. 
Cases toward the concrete end of the continuum qualify as semantic, whereas those toward the abstract end qualify as grammatical (see Blake, 2001). The function of grammatical cases is to establish the syntactic (= clause level) role of a word. The principal grammatical cases in Finnish are nominative, partitive, genitive, and accusative. The most grammatical — and also the most frequent - case is nominative, expressed by a zero morpheme in singular. The highly grammatical nature of nominative is evident from the fact that thematically it may represent the agent, patient, experiencer, recipient, or theme. The locative cases (i.e., inessive, elative, illative, adessive, ablative, allative) constitute a group that has rather unequivocally a semantic function. For example, inessive thematically expresses a location, roughly in the same sense as the English word in. Illative, another locative case, occupies the same position on the syntactic-semantic continuum as inessive, with the only difference being that it expresses a goal, roughly in the same sense as the English word into (for details, see the Materials sections of Experiments 1 and 3). On the other hand, translative exemplifies an ambiguous case that is neither clearly semantic nor clearly grammatical. It typically expresses transportation or transmutation-that is, a concrete or abstract movement toward a goal.

In the present study, we examined possible processing differences between agreement types denoted either by nominative as a grammatical case (Experiment 2) or by the aforementioned three more-or-less semantic cases (Experiments 1 and 3). As was noted previously, the information provided by inessive and illative is overwhelmingly semantic, whereas translative occupies a middle position on the syntactic-semantic continuum.

The extensive morphological marking correlates with freedom in the clause-level word order, sometimes referred to as nonconfigurationality (about Finnish word order, see, e.g., Vilkuna, 1989). The most frequent word order is SVO (subject-verb-object), but any simple dichotomy like basic and nonbasic is not particularly differentiating in Finnish. In a simple transitive sentence, which can be regarded as the basic sentence type, the SVO is canonical and OVS, for example, is noncanonical. Concerning a nonbasic sentence type-like the simple intransitive sentence-both SV(A) (subject-verb-adverbial) and (A)VS are canonical. The choice depends on the topic - the "psychological" subject - of the sentence. The topic is regularly placed at the beginning of the sentence, regardless of its grammatical function. In a language like Finnish or German, it is followed by the main verb of the sentence. English does not have these options (consider the ungrammaticality of the sentence *In London live many celebrities).

In the present study, we used nonbasic sentence types as materials for two reasons. First, according to Hyönä and Hujanen (1997), there is a clear advantage in the processing of the canonical SVO order in transitive sentences. Second, when the word order is verb-noun, the transitive verb inevitably provides some anticipatory information about the noun. To obviate this, we studied the noun on its own by using the canonical word orders of nonbasic sentence types - such as intransitive, impersonal, and detransitivized (for details, see the Materials sections of
Experiments 1 and 3)-in which the target noun phrase appeared prior to the verb.

There is an important variation in phonological transparency between the different case endings of Finnish. Notice that as a result of a very strict grapheme-phoneme correspondence, there is - in principle - no need to distinguish between phonological and orthographic. Henceforth, the term phonological transparency refers to both. For the present purpose, we identify phonological transparency with morphemic transparency - that is, with the extent to which a morpheme is transparent with respect to its stem (see Marslen-Wilson, Tyler, Waksler, \& Older, 1994). The most frequent case form - nominative singular - is also the most opaque in Finnish. This case form is expressed by a zero morpheme and is in this sense phonologically "nonexistent." The other extreme is the translative case, which is fully transparent: The morphemic boundary is clear, and the suffix has an invariable form. Inessive is almost as transparent as translative, because it has only two very similar variants. By contrast, illative is one of the most complicated cases in Finnish. The allomorphs of the illative ending are based on 6 main declensional types, which are further divided into some 40 subtypes. Although illative is phonologically very complex, it is morphologically not too different from translative and inessive, because in each case, it is possible to recognize a distinctive morpheme behind the phonological variation. In sum, the four cases-nominative, translative, inessive, and illative - constitute two intermixing continua (grammatical vs. semantic; phonological transparency vs. opacity), and combining these two makes it possible for one to differentiate syntactic and phonological aspects of agreement processing. Therefore, the studied cases make it possible to test whether phonologically opaque and purely grammatical agreement structures produce agreement effects to the same extent as do more transparent cases that have a mainly semantic function.

Although a modifier strictly follows the case of its head noun in Finnish, there is a small group of indeclinable modifiers - historical "relics," like irregular verbs in English - that can have only one form, despite the form of the head noun. Typically, some of these words also have declinable synonyms. Indeclinable modifiers constitute a theoretically very important exception, for they can be used to compare unmarked and case-marked modifierhead phrases by using totally natural and grammatical structures (see Experiment 3). These indeclinable modifiers have another important feature: They can only serve as modifiers; they can never serve as predicate nominals, as can normal declinable modifiers. Therefore, indeclinable modifiers provide structural information in that they unambiguously indicate an upcoming head-noun, but they cannot give any case (i.e., syntactic) information.

\section{The Nature of Agreement Effects}

It is not clear at what level of processing-lexical and/ or syntactic - modifier-head case agreement is operating. Since agreement is usually morphologically marked in Finnish (and in many other languages), one can feasibly argue that it may even affect the lexical access to the fullform representation of the head noun. This is so because 
the inflectional form of the head is constrained by that of the modifier. If lexical in nature, then agreement should have an impact on the early stages of processing; that is, the effect should be seen in the first-pass reading. A lexicalfrequency effect is a good example of lexical effects that show up during the first-pass reading of the critical word (often already in the first fixation duration), although the effect can spill over to the next word, a phenomenon that was first shown by Rayner and Duffy (1986). It is even possible that grammatical agreement between the modifier and the head is perceived prior to fixating the head. The results from the study of Greenberg, Healy, Koriat, and Kreiner (2004) suggest that structure-building words (articles, prepositions) and affixes are readily perceived parafoveally (i.e., prior to their fixation) in order to facilitate the processing of the syntactic structure of sentences. If this is the case, then agreement may be perceived even prior to the full lexical access of the head, provided that the head is not very long (i.e., when it falls within the span of effective vision).

On the other hand, if modifier-head agreement primarily affects integrative syntactic processing (reflecting the attachment of the modifier to its head within a phrase and the assignment of its syntactic role to the resulting noun phrase), then the bulk of the effect should appear later in the processing stream. As Clifton, Staub, and Rayner (2007) indicated in their review of 100 eye-movement studies of reading, syntactic effects are usually not immediate, whereas lexical effects typically appear in the first fixation duration. Thus, if the target word is sufficiently short to be processed in a single fixation, then an effect of grammatical agreement may not have time to evolve in the first-pass reading. The fact that lexical effects appear earlier than agreement effects has also been indicated by ERP studies. For example, Sereno, Rayner, and Posner (1998) observed a lexical-frequency effect as early as about $130 \mathrm{msec}$ after the word onset, whereas agreement effects typically manifest in P600 (Barber \& Carreiras, 2005; Coulson, King, \& Kutas, 1998; Deutsch \& Bentin, 2001; Friederici, Steinhauer, \& Frisch, 1999; Gunter, Friederici, \& Schriefers, 2000; Kaan, Harris, Gibson, \& Holcomb, 2000; Osterhout \& Mobley, 1995) or in the LAN(300-450) component (see, e.g., Barber \& Carreiras, 2005).

In line with the above reasoning, an eyetracking study of Vainio, Hyönä, and Pajunen (2003) demonstrated mostly a delayed effect for agreement processing. The agreeingmodifier condition elicited the shortest total fixation times and the least regressions, whereas the nonagreeing-modifier condition elicited the shortest gaze duration but the longest total fixation times and the most regressions. These results were taken to suggest that agreement helps integrate the modifier with the head, and integration appears to be carried out relatively late. Note, however, that this study did not examine the syntactic aspects of the case agreement; moreover, a main verb always preceded the target phrase.

\section{A Possible Role of Transparency in Agreement Processing}

To date, previous studies of modifier-head agreement have not considered the possible role that phonological transparency may play in agreement processing. In the area of morphological processing, affix saliency (Laudanna \& Burani, 1995) as well as semantic and phonological transparency (Schreuder \& Baayen, 1995) are considered important factors in determining the ease with which the morphological structure of words is acquired and processed. In addition, prefix transparency has been shown to affect lexical access in Bulgarian (Nikolova \& Jarema, 2002). More importantly, the study of Frost, Deutsch, Gilboa, Tannenbaum, and Marslen-Wilson (2000) indicated that it is possible to dissociate morphological factors from phonological and semantic factors. However, the aforementioned evidence is based on studies in which target words are presented in isolation (i.e., they did not investigate agreement processing). The following is a review of studies that have indirectly dealt with the role of transparency in agreement processing.

Deutsch, Bentin, and Katz (1999) and Deutsch and Bentin (2001) studied subject-verb gender agreement in Hebrew using three different experimental techniques. Deutsch et al. used a priming technique in combination with a word-naming task, whereas Deutsch and Bentin recorded readers' eye movement patterns and brain potentials in order to study agreement effects during sentence comprehension. Deutsch and Bentin found that the firstpass reading of incongruent predicates was slower than that of congruent predicates, but only when the gender of the predicate was morphologically marked. An examination of their example stimuli (given in Latin characters) suggests that morphological markedness also means transparency in agreement. Thus, these results are consistent with the view that transparency could play a significant role in agreement processing (however, see Experiment 2 of Deutsch et al., 1999). Although these results were obtained for subject-verb gender agreement, there is no a priori reason why transparently marked agreement would operate differently in modifier-head agreement.

In contrast, Vainio et al. (2003) presented data suggesting that phonological transparency may not influence adjectival and possessive modifier-head agreement processing in Finnish. The pattern of results was similar for a transparent adjectival modifier-head (case marking) and phonologically opaque possessive modifier-head agreement (possessive clitic). Thus, this finding suggests that phonological transparency may not modulate agreement processing.

Thus, on the basis of previous evidence, it is unclear whether transparent agreement structures produce an agreement effect more effectively (and faster) than do opaque structures.

\section{The Present Study}

The present study was comprised of three eyetracking experiments that examined the processing of modifierhead case agreement using grammatical and semantic cases that vary in the phonological transparency of agreement. The present study was also designed to examine the time course of the agreement effect - that is, whether it occurs at the lexical and/or syntactic level. The present study departed from most previous studies of modifier-head agreement in that (1) we made use of exceptionally strict 
modifier-head case agreement in Finnish, (2) we used a grammatically correct structure as the baseline condition (see also Bock \& Eberhard, 1993; Bock, Eberhard, Cutting, \& Meyer, 2004; Bock, Eberhard, Cutting, Meyer, \& Schriefers, 2001; Eberhard, Cutting, \& Bock, 2005; Pearlmutter, Garnsey, \& Bock, 1999), and (3) we studied agreement effects in sentence context during normal, continuous reading and used readers' eye-fixation patterns in order to tap into the time course of agreement processing.

\section{EXPERIMENT 1}

In Experiment 1, the processing of modifier-head agreement was studied using two phonologically transparent locative cases of Finnish - translative and inessive. As was pointed out in the introduction, inessive is a clearly semantic case, whereas translative is neither clearly semantic nor clearly grammatical.

To date, effects of modifier-head agreement have been studied earlier in Serbo-Croatian (Gurjanov, Lukatela, Moscovljević, Savić, \& Turvey, 1985), Spanish (Barber \& Carreiras, 2005), Russian (Akhutina, Kurgansky, Polinsky, \& Bates, 1999), and Finnish (Hyönä \& Hujanen, 1997; Hyönä \& Lindeman, 1994; Vainio et al., 2003). These studies indicated that the processing of the head noun is faster when it is preceded by an agreeing modifier rather than a modifier-head combination containing an agreement violation (Gurjanov et al., 1985; Hyönä \& Lindeman, 1994). Analogous effects were found for Spanish head-modifier combinations (modifier typically follows its head in Spanish; Barber \& Carreiras, 2005). In addition, Hyönä and Hujanen demonstrated an agreement effect in Finnish by using transitive verb structures. Finally, as was pointed out previously, Vainio et al. reported an agreement effect that appeared relatively late in the processing stream.

Most previous studies of agreement processing were designed to examine whether agreement generally affects processing; therefore, the linguistic manipulations have been very robust. The strongest manipulation is to compare agreeing structures with structures containing grammatical violation in modifier-head (Akhutina et al., 1999; Barber \& Carreiras, 2005; Gurjanov et al., 1985; Hyönä \& Lindeman, 1994), possessive-head (Lukatela, Kostić, Todorović, Carello, \& Turvey, 1987), subject-verb (Coulson et al., 1998; Deutsch \& Bentin, 2001; Deutsch et al., 1999; Hartsuiker, Schriefers, Bock, \& Kikstra, 2003; Nicol, Forster, \& Veres, 1997; Osterhout \& Mobley, 1995), subject-participle (Friederici et al., 1999), verbobject (MacWhinney \& Pleh, 1997; Schriefers, Friederici, \& Rose, 1998), article-noun (Barber \& Carreiras, 2005; Gunter et al., 2000), or antecedent-reflexive agreement (Osterhout \& Mobley, 1995). Another strong manipulation is to use, for example, case ambiguity (Badecker \& Kuminiak, 2007). These sorts of manipulations make it possible to inspect whether agreement affects processing in general, but this approach may not be suitable for determining whether agreement is lexical or syntactic in nature.

In order to test whether agreement processing is already manifested at the lexical level, we used relatively short target nouns that could be identified with a single fixation. If agreement operates at the lexical level, then we should find an early agreement effect being manifested in the first-pass reading time of the target noun. The effect may spill over to subsequent processing, but what is crucial is that in order for the effect to be lexical (or lexical-grammatical) in nature, its onset should be at the target noun. On the other hand, if the effect shows up only as a delayed effect, such as in the second-pass reading of the target noun, then this delayed effect is taken as evidence for processing agreement at the level of syntactic integration.

\section{Method}

\section{Participants}

Twenty-four native speakers of Finnish (students of the University of Turku) participated in the experiment. All participants had normal or corrected-to-normal vision.

\section{Apparatus}

Eye movements were collected by the EyeLink eyetracker manufactured by SR Research Ltd., Canada. The eyetracker is an infrared video-based tracking system combined with hyperacuity image processing. There are two cameras mounted on a headband (one for each eye), including two infrared LEDs for illuminating each eye. The headband weighs $450 \mathrm{~g}$ in total. The cameras sample pupil location and pupil size at the rate of $250 \mathrm{~Hz}$, and registration can be done either monocularly or binocularly. The data are collected from the dominant eye (usually the right eye) by placing the camera and the two infrared lights $4-6 \mathrm{~cm}$ away from the eye. The resolution of eye position is $15^{\prime \prime}$ of arc, and the spatial accuracy is better than $0.5^{\circ}$. Head position with respect to the computer screen is tracked via a head-tracking camera. Four LEDs are attached to the corners of the computer screen, which is viewed by the head-tracking camera once the participant sits directly facing the screen. Possible head motion is detected as movements of the four LEDs, and is compensated for online from the eye-position records.

\section{Materials}

Forty relatively short (7-8 letters) Finnish nouns both in translative $(-k s i)$ and inessive cases (-ssa or $-s s \ddot{a})$ were used as targets in the experiment. The target nouns were embedded in sentences in which they were immediately preceded by either (1) an agreeing modifier, henceforth termed the agreeing-modifier condition, or (2) a word that was not a modifier, henceforth termed the modifier-absent condition. Agreement was phonologically transparent, since the same case ending is repeated both in the modifier and in the head in both structures. The chosen case endings are both fully productive, but inessives are more frequent than translatives. Translative typically encodes concrete or abstract transition or transmutation, whereas inessive typically expresses location (analogous in meaning to the English preposition in ). ${ }^{1}$ Among the Finnish cases, inessive is located at the semantic end on the semantic-grammatical continuum, whereas translative exemplifies a more ambiguous case, which is neither clearly semantic nor clearly grammatical.

The head nouns in the four experimental conditions were controlled for lemma frequency (i.e., cumulative base frequency), surface frequency, and word length (see Table 1). The frequency measures were based on a newspaper corpus of 22.7 million word tokens (Laine \& Virtanen, 1999; Virtanen \& Pajunen, 2000). Note that since most of the words preceding the targets in the modifier-absent condition were adverbials with only one word form, the surface frequency of these words was higher than that of agreeing modifiers. The target expressions were formed concatenatively (e.g., suola + $s s a \rightarrow$ suolass $a=$ "in salt"), although in some targets, stem-internal morphophonetic changes were required (e.g., rauta + ssa $\rightarrow$ raudass $a=$ "in iron"). In both conditions, 12 out of 20 target words contained a stem-internal morphophonetic change in the translative case; the comparable numbers for inessive were 11 out of 20 and 10 
Table 1

Means and Standard Deviations for the Target Nouns of Experiment 1

\begin{tabular}{|c|c|c|c|c|c|c|c|c|}
\hline & \multicolumn{4}{|c|}{ Translative Case } & \multicolumn{4}{|c|}{ Inessive Case } \\
\hline & \multicolumn{2}{|c|}{$\begin{array}{c}\text { Modifier } \\
\text { Present }\end{array}$} & \multicolumn{2}{|c|}{$\begin{array}{c}\text { Modifier } \\
\text { Absent }\end{array}$} & \multicolumn{2}{|c|}{$\begin{array}{c}\text { Modifier } \\
\text { Present }\end{array}$} & \multicolumn{2}{|c|}{$\begin{array}{c}\text { Modifier } \\
\text { Absent }\end{array}$} \\
\hline & $M$ & $S D$ & $M$ & $S D$ & $M$ & $S D$ & $M$ & $S D$ \\
\hline Cumulative base frequency & 2.70 & 0.27 & 2.71 & 0.26 & 2.73 & 0.26 & 2.73 & 0.26 \\
\hline Surface frequency & 0.49 & 0.47 & 0.51 & 0.46 & 0.58 & 0.28 & 0.56 & 0.42 \\
\hline Word length (in letters) & 7.7 & 0.5 & 7.7 & 0.5 & 7.7 & 0.5 & 7.7 & 0.5 \\
\hline
\end{tabular}

out of 20 for the agreeing-modifier and the modifier-absent conditions, respectively.

Each target noun phrase was embedded in a separate sentence. Two matched sentence frames were created: one in which the head noun was immediately preceded by an adjectival modifier and one in which modifier was absent: Each target noun was presented once. The sentence frame in each matched pair was identical at least up to the word following the target, except for the matched target nouns; the rest of the sentence was different. To match for the semantic plausibility of the sentence frames, a rating study was conducted in which both versions of the sentence pairs were listed underneath each other. Seven participants who did not participate in the actual experiment rated the naturalness of the sentences by using one of three alternatives: Sentence 1 sounds more natural, Sentence 2 sounds more natural, or Sentences 1 and 2 sound equally natural. The exclusion criterion was that if 3 or more participants rated one sentence version to be more natural than the other, then this sentence pair was removed and a new sentence frame was constructed; this happened for three sentence pairs. The overall ratings of the final sentence sets were as follows: $70 \%$ of the sentence pairs were rated equally natural; for $14 \%$ of the pairs, Sentence 1 was rated more natural than Sentence 2, whereas the reverse was true for the remaining $16 \%$.

In order to eliminate any influence of the verb on modifier-head agreement processing, the target nouns appeared prior to the verb to which the target noun phrase was attached (unlike in Vainio et al., 2003). The target nouns appeared either in argument or adjunct phrases. An example sentence pair for both the inessive (Set 1) and the translative (Set 2) case is presented below.

Set 1. In Set 1, the inessive case (-ssa or -ssä) was used. The use of the inessive case is similar to that of the English preposition in. A total of 40 target sentences was created (i.e., 20 sentence pairs) -20 agreeing structures and 20 structures in which an agreeing modifier was absent. An example sentence pair is presented below (the target word is underlined; the morphological marking of agreement in the modifier-present version is shown in bold):

Agreeing-modifier condition

Vastoin odotuksia syvässä lammessa näyttäisi olevan enemmän kaloja kuin vuotta aiemmin.

Against expectations-deep-in-pond-in-appear-be-morefishes-than-year-earlier.

Surprisingly, there appear to be more fish in the deep pond than a year ago.

Modifier-absent condition

Vastoin odotuksia tölkissä näyttäisi olevan aiempaa suppeampi tuoteseloste.

Against expectations-jar-in-appear-be-earlier-brieferproduct specification.

Surprisingly, there appears to be a briefer product specification on the jar than earlier.

Set 2. In Set 2, the translative case $(-k s i)$ was used. A total of 40 sentences was created (i.e., 20 sentence pairs), of which 20 appeared in the agreeing-modifier condition, and 20 appeared in the modifierabsent condition. An example sentence pair is presented below (the target word is underlined; the morphological marking of agreement in the modifier-present version is shown in bold):
Agreeing-modifier condition

Voidaan kysyä, missä määrin isoksi rotaksi haukuttujulkisuuden henkilö on kuvauksensa kaltainen.

Can-question-, to what-extent-big-for-rat-for-disparagedcelebrity-is-his description-like.

It may be questioned, to what extent the celebrity, disparaged as the big rat, resembles his description.

Modifier-absent condition

Voidaan kysyä, missä määrin ankaksi haukuttu julkisuuden henkilö kävelee haukkumanimensä mukaisesti.

Can-ask-, to what-extent-duck-for-disparaged-celebritywalk-nickname-according to.

It may be questioned, to what extent the celebrity, disparaged as the duck, walks as implied by his nickname.

The 80 target sentences were mixed with 80 filler sentences of different grammatical structures (transitive, intransitive, and copula sentences). Of the filler sentences, $46 \%$ obeyed a SV order and $64 \%$ a VS order; 25 filler sentences included an inessive case and 11 sentences included a translative case somewhere in the sentence. The target word never appeared in the beginning or at the end of a text line. The target sentences were presented in Courier font, left justified, one at a time, roughly at the center of the computer screen. With a viewing distance of about $65 \mathrm{~cm}$, one character space subtended approximately $0.5^{\circ}$ of visual angle. The sentences were presented in two blocks, so that the two members of each sentence pair never appeared in the same block. The order of blocks was counterbalanced across participants; within a block, the order of sentences was individually randomized.

\section{Procedure}

Prior to the experiment, the eye tracker was calibrated using a nine-point calibration grid that extended over the entire computer screen. Prior to each sentence, the calibration was checked by presenting a fixation point on the left corner of the screen coinciding with the location of the first letter of the sentence about to be presented. If needed, the calibration was automatically corrected.

Participants were instructed to read sentences for comprehension at their own pace. They were further told that periodically they would be asked to paraphrase the last sentence that they had just read in order to make sure that they attended to what they read. However, we emphasized that the task was to comprehend-not to memorize - the sentences. Participants were asked to paraphrase the sentence after approximately every 10th sentence. The experimental session lasted a maximum of $45 \mathrm{~min}$.

\section{Results}

A set of 2 (case type: inessive vs. translative) $\times 2$ (modifier presence: agreeing modifier vs. modifier absent) ANOVAs was computed on the data. In the participant analyses, both variables were within-participant variables; in the item analyses, case type was a between-item variable and modifier presence was a within-item variable.

Four eye-fixation measures were calculated for the target word: first fixation duration, gaze duration (sum of all 
first-pass fixations made before leaving the word), rereading time (the time spent refixating the word after its firstpass reading), and the probability of rereading the target (i.e., the probability of refixating the word after its firstpass reading). Rereading fixations made after reaching the sentence end were excluded from the analyses, since it is highly unlikely that this type of rereading reflects local agreement processing. Note that when no reinspections were made, rereading time was set to 0 . Moreover, two measures were also calculated for the word following the target word $(n+1)$ : first fixation duration and gaze duration. All trials were excluded in which there was a track loss or in which the target noun was initially skipped (i.e., not fixated during the first-pass reading). The missing data amounted to $5.5 \%$. Since there was a frequency difference in word $n-1$, in the statistical analyses of the first-pass fixation-time measures (first fixation duration and gaze duration), $n-1$ frequency was entered as a covariate. ${ }^{2}$ This was done because previous evidence (see, e.g., Rayner \& Duffy, 1986) suggests that a frequency effect may carry over to the next word.

Early effects in agreement processing may be detected by first fixation and gaze duration on the target word; somewhat delayed effects are observed in the measures for word $n+1$; the latest recorded effects may be seen in the rereading fixations on the target. The means and standard deviations for each eye fixation measure are presented in Table 2.

\section{Target Word}

First fixation duration. The main effects of modifier presence $\left[F_{1}(1,23)=1.86, p=.19 ; F_{2}(1,75)<1\right]$ and case $\left[F_{1}(1,23)=2.29, p=.14 ; F_{2}(1,75)<1\right]$ were nonsignificant; so was the modifier presence $\times$ case interaction $\left(F_{1}, F_{2}<1\right)$. One may note that the majority of target words were read with a single fixation (the probability of single fixation was .69 for the agreeing-modifier and .71 for the modifier-absent conditions, respectively).

Gaze duration. The main effect of modifier presence was not significant $\left[F_{1}(1,23)=1.12, p=.30 ; F_{2}(1,75)<1\right]$. On the other hand, there was a significant main effect of case in the by-participant analysis $\left[F_{1}(1,23)=6.60, M S_{\mathrm{e}}=\right.$ $\left.5,850.99, p=.02 ; F_{2}(1,75)<1\right]$. The modifier presence $\times$ case interaction was nonsignificant $\left(F_{1}, F_{2}<1\right)$.

Rereading time. All effects remained nonsignificant (all $p s>.245$ ).
Probability of rereading. A significant main effect of modifier presence emerged in the probability of rereading $\left[F_{1}(1,23)=5.85, M S_{\mathrm{e}}=.010, p=.02 ; F_{2}(1,19)=4.38\right.$, $\left.M S_{\mathrm{e}}=.011, p=.05\right]$. The rereading probability was $4.8 \%$ smaller when the target word was preceded by a modifier. On the other hand, the main effect of case $\left(F_{1}, F_{2}<1\right)$ and the modifier presence $\times$ case interaction $\left[F_{1}<1\right.$; $F_{2}(1,19)=1.02, p=.33$ ] were nonsignificant.

\section{Word $n+1$}

First fixation duration. There was a significant main effect of modifier presence in first fixation duration $\left[F_{1}(1,23)=7.33, M S_{\mathrm{e}}=629.06, p=.01 ; F_{2}(1,38)=\right.$ $\left.9.17, M S_{\mathrm{e}}=297.68, p<.01\right] .{ }^{3}$ First fixation duration on word $n+1$ was 17 msec shorter when word $n-1$ was a modifier than when it was a nonmodifier. There was neither a main effect of case (of the target noun) $\left[F_{1}(1,23)=\right.$ $\left.2.13, p=.16 ; F_{2}(1,38)<1\right]$ nor a modifier presence $\times$ case interaction $\left(F_{1}, F_{2}<1\right)$.

Gaze duration. A significant main effect of modifier presence emerged $\left[F_{1}(1,23)=21.40, M S_{\mathrm{e}}=895.76, p<\right.$ $.01 ; F_{2}(1,38)=15.17, M S_{\mathrm{e}}=1,058.99, p<.01$. Gaze duration was $31 \mathrm{msec}$ shorter in the modifier-present condition than in the modifier-absent condition. The main effect of case and the modifier presence $\times$ case interaction remained nonsignificant $\left(F_{1}, F_{2}<1\right)$.

\section{Discussion}

The analyses of Experiment 1 yielded an agreement effect in the first fixation duration and gaze duration on word $n+1$, as well as in the probability of rereading of the target word. Thus, the results of Experiment 1 provide evidence for a delayed effect of agreement. The earliest point in time to observe an effect of agreement was when readers fixated on the word following the target noun. However, we found no evidence for an agreement effect in the firstpass fixation time of the target. In sum, the results of Experiment 1 are consistent with the view that the observed agreement effect is not lexical but syntactic in nature.

\section{EXPERIMENT 2}

A skeptic may argue that what we interpret in Experiment 1 as an agreement effect may in fact be based on phonological priming, since the same suffix is repeated

Table 2

Means and Standard Deviations As a Function of Modifier Presence and Case Type in Experiment 1

\begin{tabular}{|c|c|c|c|c|c|c|c|c|c|}
\hline \multirow[b]{3}{*}{ Word } & \multirow[b]{3}{*}{ Measure } & \multicolumn{4}{|c|}{ Translative Case } & \multicolumn{4}{|c|}{ Inessive Case } \\
\hline & & \multicolumn{2}{|c|}{$\begin{array}{l}\text { Modifier } \\
\text { Present }\end{array}$} & \multicolumn{2}{|c|}{$\begin{array}{c}\text { Modifier } \\
\text { Absent }\end{array}$} & \multicolumn{2}{|c|}{$\begin{array}{l}\text { Modifier } \\
\text { Present }\end{array}$} & \multicolumn{2}{|c|}{$\begin{array}{c}\text { Modifier } \\
\text { Absent }\end{array}$} \\
\hline & & $M$ & $S D$ & $M$ & $S D$ & $M$ & $S D$ & $M$ & $S D$ \\
\hline \multirow[t]{4}{*}{$n$} & First fixation duration (msec) & 238 & 42 & 226 & 47 & 239 & 41 & 220 & 42 \\
\hline & Gaze duration (msec) & 306 & 66 & 295 & 79 & 301 & 70 & 278 & 80 \\
\hline & Rereading time (msec) & 58 & 32 & 62 & 41 & 58 & 39 & 70 & 40 \\
\hline & Probability of rereading (\%) & 22.9 & 10.9 & 25.7 & 13.7 & 20.6 & 12.2 & 27.5 & 14.9 \\
\hline \multirow[t]{2}{*}{$n+1$} & First fixation duration (msec) & 210 & 42 & 223 & 53 & 202 & 46 & 217 & 52 \\
\hline & Gaze duration (msec) & 262 & 64 & 291 & 83 & 267 & 82 & 285 & 95 \\
\hline
\end{tabular}


both in the modifier and the head. However, we consider it unlikely, because a priming effect should show up relatively early in the processing time line. Nevertheless, if this is the case, then by using a totally opaque agreement structure - nominative singular (a purely grammatical case) - the agreement effect should disappear. This hypothesis was put to a test in Experiment 2. On the other hand, if the results of Experiment 1 reflect mainly syntactic agreement, then a delayed effect of agreement should be found even without overt phonological signaling of modifier-head agreement. Finally, the use of nominative singular makes it possible to tightly control for the surface frequency of word $n-1$ between the modifier-present and the modifier-absent conditions, which was not possible in the materials used in Experiment 1.

For Experiment 2, two conditions were created: one in which the target noun was preceded by a noninflected adjective modifier, and another in which the modifier was absent. Experiment 2 differed from Experiment 1 in three important respects. First, a purely grammatical case (nominative) was used. Second, the adjectival modifier appeared in the noninflected base form (i.e., the nominative singular) in which there is no transparent morphophonemic cue to mark modifier-head agreement, because the nominative singular is signaled by a zero morpheme in Finnish. Third, the frequency of the word preceding the target noun was tightly matched across the two conditions. A delayed agreement effect would suggest that agreement exerts its effect at the syntactic level, whereas a null result would indicate that the results of Experiment 1 may reflect morphophonological priming.

\section{Method}

Participants. Thirty-four native speakers of Finnish (students of the University of Turku) participated in the experiment. All participants had normal or corrected-to-normal vision. None had taken part in the previous experiment.

Apparatus. The apparatus was the same as that in Experiment 1.

Materials. Sixteen Finnish nouns in the nominative (noninflected) case were used as targets. The target nouns were embedded in sentences in which the target noun was preceded by a noninflected adjective modifier or in which the modifier was deleted. In the modifier-absent condition, word $n-1$ was typically an adverbial. In four target-sentence pairs, the verb preceded the target phrase; in the remaining 12 target sentence pairs, the verb appeared after the target phrase. Unlike in Experiment 1, the same target words were presented in both conditions; therefore, their frequencies are naturally matched. The average logarithmic frequency per million values of the target nouns and their length in letters (standard deviations in parentheses) are as follows: cumulative base frequency, $1.11(0.77)$; surface frequency, $0.48(0.73)$; and word length $7.3(0.6)$.

The target word never appeared in the beginning or end of a text line. In the example below, the target noun is underlined; in the modifier-absent condition, the modifier shown in the parentheses was not presented.

Ajoittain näkyi puiden lomitse (vanttera) pihlaja, jonka runkoon monet nuoret olivat tehneet puumerkkinsä.

Occasionally-was seen-trees-between-(sturdy)-rowanwhose-trunk-many-youth-was-made-mark-theirs.

Occasionally a (sturdy) rowan, on whose trunk many teenagers had written their initials, was seen between the trees.

Thirty-two target sentences were created, of which two stimulus lists were prepared. Each list contained 16 target sentences and 84 filler sentences that conformed to different grammatical structures. Thus, each list comprised only one member of each sentence pair, so that both lists contained eight target sentences for the modifier-present condition and eight target sentences for the modifier-absent condition. Each participant read only one list; each list was read by 17 participants. Within the list, the order of sentences was individually randomized. Seventy percent of the filler sentences appeared in the SV order, whereas the remaining $30 \%$ conformed to a VS order.

Procedure. The procedure was identical to that in Experiment 1.

\section{Results}

Paired-samples two-tailed $t$ tests (modifier present vs. absent) were computed on the eye-fixation data both by participants and by items. The same dependent measures as those in Experiment 1 were computed for the target noun and the word following the target (word $n+1$ ). The means and standard deviations are presented in Table 3. The same exclusion criteria as those in Experiment 1 were applied. The missing data amounted to $2.2 \%$.

Target word. There were no significant differences in either of the first-pass fixation-time measures (first fixation duration and gaze duration; $t_{1}, t_{2}<1$ ). Note also that the probability of making a single fixation on the target did not differ between the two conditions (it was .66 for the modifier-present and .67 for the modifier-absent conditions, respectively).

However, rereading time was $21 \mathrm{msec}$ shorter in the modifier-present condition $\left[t_{1}(1,33)=2.15, S E M=9.71\right.$, $\left.p=.04 ; t_{2}(1,15)=2.48, S E M=8.67, p=.03\right]$. Somewhat surprisingly, this difference did not show up in the probability of rereading the target $\left[t_{1}=1.28, S E M=.035\right.$, $\left.p=.21 ; t_{2}=1.52, S E M=.031, p=.15\right]$.

Word $n+1$. No reliable differences were observed for word $n+1$ in any of the analyzed measures (see Table 3; all $\left.t_{1}, t_{2}<1\right)$.

\section{Discussion}

The results of Experiment 2 indicate that there was no difference in the initial processing of the target noun or the word following the target between the modifier-present and modifier-absent conditions, as indexed by the firstpass fixation-time measures. However, there was a later effect of modifier presence, which showed up in the rereading time of the head noun. In other words, when a modifier preceded the head noun, there was less rereading

Table 3

Means and Standard Deviations As a Function of Modifier Presence in Experiment 2

\begin{tabular}{|c|c|c|c|c|c|}
\hline \multirow[b]{3}{*}{ Word } & \multirow[b]{3}{*}{ Measure } & \multicolumn{4}{|c|}{ Nominative Case } \\
\hline & & \multicolumn{2}{|c|}{$\begin{array}{c}\text { Modifier } \\
\text { Present }\end{array}$} & \multicolumn{2}{|c|}{$\begin{array}{c}\text { Modifier } \\
\text { Absent }\end{array}$} \\
\hline & & $M$ & $S D$ & $M$ & $S D$ \\
\hline \multirow[t]{4}{*}{$n$} & First fixation duration (msec) & 233 & 48 & 240 & 45 \\
\hline & Gaze duration (msec) & 305 & 84 & 304 & 82 \\
\hline & Rereading time (msec) & 30.0 & 40.8 & 49.1 & 52.3 \\
\hline & Probability of rereading $(\%)$ & 13.2 & 14.9 & 17.5 & 18.4 \\
\hline \multirow[t]{2}{*}{$n+1$} & First fixation duration (msec) & 212 & 51 & 206 & 43 \\
\hline & Gaze duration (msec) & 297 & 115 & 295 & 122 \\
\hline
\end{tabular}


time spent in the target noun than when the target noun was not modified by an adjective.

These results replicate the delayed modifier-head agreement effect that was obtained in Experiment 1. The delayed effect is also consistent with that observed by Hyönä and Hujanen (1997) for sentence subjects. The main differences between Experiments 1 and 2 are that in Experiment 1, primarily semantic cases were used, and agreement was both phonologically and morphologically transparent. In Experiment 2, however, opaque grammatical agreement was used. The similar pattern of results across the two experiments suggests that overt morphophonological transparency is not needed to obtain a reliable agreement effect. Thus, these results are compatible with the view that the observed agreement effects reflect syntactic integration within and between phrases. The results also suggest that modifier-head agreement effects are obtainable both with semantic and grammatical cases.

We argued above that the delayed agreement effect reflects syntactic integration. It is easier to assign a syntactic role to the head noun and integrate it to the preceding context when it is preceded by a modifier that already entails the relevant syntactic information. However, a critic might argue that the effect is a reflection of a mere modifierpresence effect or of a conjoint frequency difference: An adjective-noun combination is likely to be more frequent than an adverbial-noun combination. Thus, we conducted a coarse-grained corpus analysis in a 31.3 million wordtoken newspaper corpus (Virtanen \& Pajunen, 2000). Indeed, there were 1.08 million adjective-noun pairs and only 0.36 million adverbial-noun pairs in the corpus, which gives a 3:1 ratio in favor of adjective-noun combinations. Note that there is evidence from Finnish that a 9:1 ratio in structural frequency causes a significant effect in online processing (see Hyönä \& Vainio, 2001). Thus, we cannot rule out the conjoint-frequency account. These issues were addressed in Experiment 3.

\section{EXPERIMENT 3}

The first aim of Experiment 3 was to rule out the possibility that the observed effect either reflects a modifierpresence effect or that a conjoint frequency difference between adjective-noun and adverbial-noun combinations is responsible for the effects that were obtained in Experiments 1 and 2. If either explanation is true, then the use of a modifier in both conditions should wipe out the effect. On the other hand, a delayed agreement effect would imply that it is genuine and syntactic in nature.

The second aim was to further examine whether the delayed agreement effect that was observed in Experiment 1 is a genuine morphological-agreement effect (as was suggested by the results of Experiment 2) that was not solely driven by phonological transparency present in the marking of modifier-head agreement (Experiment 1).

In order to achieve these goals, we made use of two features of Finnish: (1) Even though modifier-head agreement is typically phonologically transparent in Finnish, inflectional paradigms exist when this is not the case. (2) There exists a small set (about 10) of indeclinable modifiers that always appear in the base form, regardless of the case ending of the head noun. Thus, by using these indeclinable modifiers, we were able to contrast an agreeing structure to a nonagreeing structure without introducing a grammatical category difference (cf. Experiments 1 and 2). What is also characteristic of these indeclinable modifiers is that, unlike other modifiers, they can only appear as modifiers, but they cannot be used as predicate nominals. Therefore, these indeclinable modifiers provide an unambiguous signal that a head noun will be the next word. On the other hand, they do not provide any information about the morphological case (i.e., syntactic information) of the head. Thus, the use of these modifier conditions can disentangle effects resulting from syntactic predictability from those resulting from grammatical agreement. Note that there are no grammatical constraints about when to use an indeclinable versus declinable modifier.

In Experiment 3, the target head noun was preceded by a modifier in both experimental conditions. In one condition, the head noun was preceded by an inflected modifier that agreed morphologically with the head, but the morphological agreement was phonologically nontransparent ( pieneen aitioon = "into the small balcony") - henceforth termed the case-marked modifier condition. In the other condition, the target noun was preceded by an indeclinable modifier that always appears in one and the same form ( pikku aitioon $=$ "into the small balcony") —-henceforth termed the unmarked-modifier condition. In order to have the agreement appear in a phonologically less transparent form, we used the illative case (the equivalent of the English preposition into) that can have different phonological variants depending on several factors, as will be clarified in more detail in the following Materials section. Importantly, in our stimulus set, the inflectional form denoting the illative case was always phonologically different between the modifier and the head (i.e., the same inflectional variant as that in Experiment 1 was not repeated). Thus, readers cannot readily assign modifier-head agreement on the basis of phonological cues, whereas morphologically, assignment is not much different from translative and inessive-the cases used in Experiment 1. Illative is similar to inessive, since it occupies the same position on the semantic-grammatical continuum (both are mainly semantic cases). On the other hand, thematically, illative denotes a goal, similarly to translative.

\section{Method}

\section{Participants}

Sixty native speakers of Finnish (students of University of Turku) participated in the experiment. All participants had normal or correctedto-normal vision. None had taken part in the previous experiments.

\section{Apparatus}

The apparatus was the same as that in Experiment 1.

\section{Materials}

Twenty Finnish nouns in the illative case were used as the targets. Each target noun was embedded in two sentence frames that were identical except for the modifier preceding the target word. Similarly to Experiments 1 and 2, the target phrase preceded the main verb. In one condition, the modifier was one of the few indeclinable modifiers existing in Finnish, which appear only in the base form-that is, 
nominative singular. Note that although these indeclinable modifiers (e.g., pikku = "small") signal that a head will immediately follow them, they do not signal in any way the morphological form (i.e., the syntactic status) of the head. In the other condition, the head noun was preceded by a declinable modifier that agreed morphologically with its head, but the agreement was not phonologically transparent. In order to have the modifier-head agreement appear in a phonologically less transparent form, we used the illative case (the equivalent of the English preposition into). Illative is formally less transparent, since it comes in several phonological variants. The factors affecting the use of different phonological variants are as follows:

(1) consonant gradation of the stem (i.e., the stem internal changes when inflected),

(2) many declension types, including six main declension types and 40 subtypes,

(3) the number of syllables in the word,

(4) the last vowel of the word.

The modifier-target word pairs were selected so that the suffix variant was always different between the modifier and the head. Below is an example pair of the two stimulus conditions (pieneen aitioon comprises the case-marked modifier condition and pikku aitioon the unmarked condition).

Valokuvan perusteella pieneen / pikku aitioon ahtautunut ryhmä nautti kovasti toistensa seurasta.

Photograph-based on-small-into / small-balcony-intocongested-group-enjoyed-greatly-each other's-company.

Based on the photograph, the group congested into a small balcony greatly enjoyed each other's company.

Note that the target nouns in both conditions were the same and that the target phrases preceded the main verbs. Also, some- but not all - of the modifiers were similar in meaning across the two conditions. However, in order to be sure that these modifier-head pairs were equally plausible between the two conditions, we did a rating test with 20 participants who did not participate in any of the reading experiments. This was done because Thornton and MacDonald (2003), for example, showed that plausibility affects subject-verb agreement in English. The participants evaluated the word pairs on a scale of $1-7$, in which a higher number indicated higher plausibility. The materials were split into two lists; the two lists were counterbalanced across participants. Each participant saw only one member of each word pair. Each participant evaluated 68 word pairs, 10 of which were case-marked modifier-target and 10 unmarked modifier-target pairs. The order of the word pairs was individually randomized within the list. All word pairs were shown in nominative singular (e.g., pikku aitio vs. pieni aitio = "small balcony"), because the task was used to evaluate their semantic plausibility. The results showed that the pairs were equally plausible $(t<1)$; the averages were $5.5(S D=1.2)$ for the case-marked and $5.3(S D=0.6)$ for the unmarked modifier condition, respectively.

The average logarithmic frequency per million values of the target nouns and their length in letters ( $S D$ s in parentheses) are as follows: cumulative base frequency $1.72(0.55)$, surface frequency 0.39 (0.55), and word length 8.1 (1.4). The modifiers in the two experimental conditions differed somewhat in surface frequency and length. The logarithmic frequency per million values of the modifiers and their length in letters (SDs in parentheses) are as follows: case-marked modifiers, cumulative base frequency 2.45 (0.69), surface frequency $0.65(0.98)$, and word length $6.6(0.8)$; unmarked modifiers, cumulative base frequency $2.38(0.89)$, surface frequency $2.37(0.90)$, and word length $4.4(0.8)$. These results are unavoidable, because the surface frequency of unmarked modifiers is inevitably higher than that of case-marked modifiers when the cumulative base frequency is matched. Also by definition, the case-marked modifiers are longer than unmarked modifiers.

The 20 target-sentence pairs were mixed with 92 filler sentences that conformed to different grammatical structures. Seventy-six percent of the filler sentences obeyed the SV word order, whereas the remaining $24 \%$ obeyed a VS word order. An illative case appeared in 29 filler sentences. The target word never appeared at the beginning or end of a text line. Two stimulus lists were prepared. Each list comprised only one member of each sentence pair, so that both lists contained 10 target sentences in the case-marked modifier and 10 target sentences in the unmarked modifier condition. Each participant read only one list. Within the list, the order of sentences was individually randomized. The list was presented in two blocks. Every modifier appeared once in each block; thus, each modifier was read twice by each participant.

\section{Procedure}

The procedure was identical to that in Experiment 1.

\section{Results}

Paired-samples two-tailed $t$ tests were computed with the data. The same dependent measures as those in Experiment 2 were computed. The means and standard deviations are presented in Table 4. The same exclusion criteria were used as those previously. The missing data amounted to $5.6 \%$. Because of a surface frequency difference between the case-marked and unmarked modifiers (i.e., word $n-1$ ), their frequency was used as a covariate in the analyses of the first fixation duration of the target, which was similar to Experiment 1 (see note 2). We did not do this for gaze duration, since there was no effect even without a covariate.

\section{Target Word}

First fixation duration. There was no significant difference between the two modifier conditions $\left(t_{1}<1\right.$, $\left.t_{2}<1\right)$. The probability of reading the target with a single fixation was .62 for the case-marked condition and .61 for the unmarked condition. These probabilities compare favorably with those observed for the targets in Experiments 1 and 2 .

Gaze duration. There was no effect in gaze duration $\left[t_{1}(1,59)=1.26, S E M=8.17, p=.21 ; t_{2}<1\right]$.

Rereading time. There was a significant effect of modifier type in rereading time $\left[t_{1}(1,59)=3.80, S E M=\right.$ $\left.10.07, p<.01 ; t_{2}(1,19)=2.16, S E M=17.35, p=.04\right]$. Rereading time was $38 \mathrm{msec}$ shorter in the case-marked than in the unmarked modifier condition.

Probability of rereading. There was also a significant effect of modifier type in the probability of rereading

Table 4

Means and Standard Deviations As a Function of Modifier Type in Experiment 3

\begin{tabular}{|c|c|c|c|c|c|}
\hline \multirow[b]{3}{*}{ Word } & \multirow[b]{3}{*}{ Measure } & \multicolumn{4}{|c|}{ Illative Case } \\
\hline & & \multicolumn{2}{|c|}{$\begin{array}{l}\text { Case-Marked } \\
\text { Modifier } \\
\end{array}$} & \multicolumn{2}{|c|}{$\begin{array}{l}\text { Unmarked } \\
\text { Modifier }\end{array}$} \\
\hline & & $M$ & $S D$ & $M$ & $S D$ \\
\hline \multirow[t]{4}{*}{$n$} & First fixation duration (msec) & 238 & 46 & 227 & 36 \\
\hline & Gaze duration (msec) & 322 & 80 & 312 & 70 \\
\hline & Rereading time (msec) & 80 & 67 & 118 & 85 \\
\hline & Probability of rereading $(\%)$ & 25.3 & 16.8 & 35.3 & 21.1 \\
\hline \multirow[t]{2}{*}{$n+1$} & First fixation duration (msec) & 222 & 41 & 231 & 41 \\
\hline & Gaze duration (msec) & 297 & 86 & 300 & 73 \\
\hline
\end{tabular}


$\left[t_{1}(1,59)=4.34, S E M=.023, p<.01 ; t_{2}(1,19)=2.36\right.$, $S E M=.041, p=.03]$. The probability of rereading the target was $10.0 \%$ smaller when the preceding word was a case-marked modifier.

To sum up, a reliable agreement effect was observed in both the rereading time and the probability of rereading the target noun. By showing that an agreement effect emerges with some time delay, these results converge with those observed in Experiments 1 and 2.

\section{Word $n+1$}

For word $n+1$, no reliable effects of modifier type were observed in first fixation duration $\left[t_{1}(1,56)=1.73\right.$, $\left.S E M=5.39, p=.09 ; t_{2}(1,19)<1\right]$ or in gaze duration $\left(t_{1}, t_{2}<1\right)$ (see note 3$)$.

\section{Discussion}

Experiment 3 yielded three main findings. First, it demonstrated that the results of Experiments 1 and 2 cannot be interpreted as a modifier-presence effect, since we observed an agreement effect when both experimental conditions included a modifier. Similarly, Experiment 3 indicates that the agreement effects that were obtained in Experiments 1 and 2 are not viably explained as a structural frequency effect (adjective-noun pairs occurring more frequently in Finnish than adverbial-noun pairs). Rather, we are dealing with a genuine agreement effect. Second, an agreement effect is also found when morphological agreement between modifier and head is not phonologically fully transparent, thus replicating the results of Experiment 2. However, Experiments 2 and 3 differ from each other in one important respect. In Experiment 2, a grammatical case was used, whereas Experiment 3 tested agreement effects with a case that is semantic in nature. Despite this difference, the results converge in demonstrating an agreement effect for both case types. Third, similarly to Experiments 1 and 2, the agreement effect appeared as a delayed effect - as an increased need for rereading the head noun - when there was no morphological agreement between the modifier and head.

In sum, the results of Experiment 3 indicate that it is possible to obtain an agreement effect even with mainly morphological cues (i.e., in the absence of phonologically fully transparent agreement structures). Thus, together with Experiment 2, our data indicate that phonological transparency is not needed for eliciting modifier-head agreement effects.

\section{GENERAL DISCUSSION}

The aim of the present study was to investigate the nature and locus of modifier-head agreement effects during sentence comprehension in Finnish. As was mentioned in the introduction, we made use of some interesting characteristics of Finnish — such as when the modifier always precedes its head and when the modifier agrees with its head in both case and number. In other words, the same morphological suffix is attached to both the modifier and the head. Typically, the attached inflectional suffix denoting modifier-head agreement is phonologically identical, which makes the agreement fully transparent (Experiment 1), although there are exceptions to this general rule (Experiments 2 and 3 ).

The following are the main conclusions of the present study.

There exists a genuine modifier-head agreement effect. This conclusion is made on the basis of the generality and consistency of the observed effects. Across the three experiments, we employed inflectional cases that occupy different positions on the semantic-grammatical continuum in the Finnish case system, from predominantly semantic to clearly grammatical. Moreover, we studied agreement effects with agreement structures that were phonologically completely transparent (Experiment 1), phonologically very complex but morphologically clear (Experiment 3 ), and opaque (Experiment 2). Despite marked differences in the syntactic and thematic status of the target noun phrases on one hand and in the phonological opacity on the other hand, we consistently obtained reliable delayed effects of agreement. This result strongly speaks for the generality of the effect. Moreover, the fact that agreement effects are also obtained with phonologically opaque agreement structures rules out the possibility that the effect is primarily caused by repetition priming (i.e., in the transparent structures, the same letter cluster is repeated both in the modifier and the head). Finally, the observed effects reflect a genuine modifier-head agreement effect in the sense that they were not influenced by the main verb, which appeared after the target noun phrase.

The agreement effect is delayed and syntactic in nature, not affecting lexical access. The present study indicated that the agreement effect needs some time to develop, since it was observed in the first-pass fixation time of the word following the critical target and/or in the probability of rereading and rereading time of the target noun, but never in the first-pass reading of the target. The delayed nature of the effect is compatible with the view that it reflects syntactic integration within the noun phrase and between two consecutive phrases. A delayed agreement effect is generally consistent with ERP studies of agreement (Barber \& Carreiras, 2005; Coulson et al., 1998; Deutsch \& Bentin, 2001; Friederici et al., 1999; Gunter et al., 2000; Kaan et al., 2000; Osterhout \& Mobley, 1995), which have observed agreement effects in the P600 component.

A critic may argue that the delayed effects may in fact reflect delayed lexical access to the full-form representation of the target noun. We consider this possibility highly unlikely, for three reasons. First, previous eye-movement studies of lexical processing have not found lexical effects that appear only as a delayed effect. Lexical effects may spill over to the next word (Rayner \& Duffy, 1986), but they do not manifest as pure delayed effects. Second, delaying access of the inflected forms would be very maladaptive in reading Finnish (and other highly inflected languages), a language in which most content words appear in an inflected form. It would mean that readers, as a rule, would be simultaneously completing access to at least two words - the currently fixated and the previously fixated ones. Third, previous evidence from Finnish implies that the processing of case inflections in reading operates at 
the syntactic level. Hyönä, Vainio, and Laine (2002) compared the identification of inflected versus monomorphemic words both in isolation and in a sentence context, and they found a morphological complexity effect-longer processing time for inflected than for monomorphemic words - only when the target words were presented in isolation. This finding demonstrates that syntactic constraints can influence the processing of case inflections and hence is generally consistent with the view that case inflections are processed at the syntactic level — a possibility that was also mentioned by Taft (1994).

Are the observed agreement effects only specific to Finnish? We think that this is highly unlikely. Rather, it is likely that modifier-head agreement effects may be found in languages that fulfill the following two criteria: (1) the modifier precedes its head, and (2) agreement between the modifier and head is either morphologically transparent or has a syntactic function. Several languages and language groups exist that fulfill these criteria-for example, Baltic-Finnic (Estonian, Finnish), Slavic (Czech, Polish, Russian, Ukrainian), and Germanic (especially German and Icelandic) languages. In addition, we assume that modifier-head agreement is somewhat less robust in languages in which the modifier can also follow its head, such as Romance languages (Catalan, French, Italian, Portuguese, Romanian, Sardinian, and Spanish).

In conclusion, the present study demonstrates that readers make use of modifier-head agreement regardless the type of case (grammatical-semantic), the phonological or morphological transparency, or the grammatical status of the noun phrase. The present study also demonstrates that establishing agreement is a time-consuming process that is not completed before the reader fixates away from the noun phrase. This finding suggests that agreement does not speed up lexical access; instead, agreement influences syntactic integration.

\section{AUTHOR NOTE}

We thank Esa Itkonen for his comments on an earlier version of the manuscript. S.V. was supported by the Finnish Graduate School in Language Studies (Langnet). J.H. acknowledges the support of Suomen Akatemia (the Academy of Finland). This study was also partly supported by Grant 118404 from the Academy of Finland to Raymond Bertram. Correspondence concerning this article should be addressed to S. Vainio, Department of Psychology, University of Turku, Turku, Finland FIN-20014 (e-mail: sepvai@utu.fi).

\section{REFERENCES}

Akhutina, T., Kurgansky, A., Polinsky, M., \& Bates, E. (1999). Processing of grammatical gender in a three-gender system: Experimental evidence from Russian. Journal of Psycholinguistic Research, 28, 695-713.

Badecker, W., \& KuminiaK, F. (2007). Morphology, agreement and working memory retrieval in sentence production: Evidence from gender and case in Slovak. Journal of Memory \& Language, 56, 65-85.

BARber, H., \& CARREIRAS, M. (2005). Grammatical gender and number agreement in Spanish: An ERP comparison. Journal of Cognitive Neuroscience, 17, 137-153.

Blake, B. J. (2001). Case. Cambridge: Cambridge University Press.

Bock, K., \& Eberhard, K. M. (1993). Meaning, sound and syntax in English number agreement. Language \& Cognitive Processes, 8, 57-99.

Bock, K., Eberhard, K. M., Cutting, J. C., \& Meyer, A. S. (2004).
Producing number agreement: How pronouns equal verbs. Journal of Memory \& Language, 51, 251-278.

Bock, K., Eberhard, K. M., Cutting, J. C., Meyer, A. S., \& SchriefERS, H. (2001). Some attractions of verb agreement. Cognitive Psychology, 43, 83-128.

Clifton, C., JR., Staub, A., \& Rayner, K. (2007). Eye movements in reading words and sentences. In R. P. G. van Gompel, M. H. Fischer, W. S. Murray, \& R. L. Hill (Eds.), Eye movements: A window on mind and brain (pp. 341-371). Amsterdam: Elsevier.

Coulson, S., King, J. W., \& Kutas, M. (1998). Expect the unexpected: Event-related brain response to morphosyntactic violations. Language \& Cognitive Processes, 13, 21-58.

Deutsch, A., \& Bentin, S. (2001). Syntactic and semantic factors in processing gender agreement in Hebrew: Evidence from ERPs and eye movements. Journal of Memory \& Language, 45, 200-224.

Deutsch, A., Bentin, S., \& Katz, L. (1999). Semantic influence on processing gender agreement: Evidence from Hebrew. Journal of Psycholinguistic Research, 28, 515-535.

Eberhard, K. M., Cutting, J. C., \& Bock, K. (2005). Making syntax of sense: Number agreement in sentence production. Psychological Review, 112, 531-559.

Friederici, A. D., Steinhauer, K., \& Frisch, S. (1999). Lexical integration: Sequential effects of syntactic and semantic information. Memory \& Cognition, 27, 438-453.

Frost, R., Deutsch, A., Gilboa, O., Tannenbaum, M., \& MarslenWilson, W. (2000). Morphological priming: Dissociation of phonological, semantic, and morphological factors. Memory \& Cognition, 28, 1277-1288.

Greenberg, S. N., Healy, A. F., Koriat, A., \& Kreiner, H. (2004). The GO model: A reconsideration of the role of structural units in guiding and organizing text on line. Psychonomic Bulletin \& Review, 11, 428-433.

Gunter, T. C., Friederici, A. D., \& Schriefers, H. (2000). Syntactic gender and semantic expectancy: ERPs reveal early autonomy and late interaction. Journal of Cognitive Neuroscience, 12, 556-568.

Gurjanov, M., Lukatela, G., Moscovljević, J., Savić, M., \& TuRVEY, M. T. (1985). Grammatical priming of inflected nouns by inflected adjectives. Cognition, 19, 55-71.

Hartsuiker, R. J., Schriefers, H. J., Bock, K., \& Kikstra, G. M. (2003). Morphophonological influences on the construction of subject-verb agreement. Memory \& Cognition, 31, 1316-1326.

HyönÄ, J., \& HuJANEN, H. (1997). Effects of case marking and word order on sentence parsing in Finnish: An eye fixation analysis. Quarterly Journal of Experimental Psychology, 50A, 841-858.

HyönÄ, J., \& LindEMAN, J. (1994). Syntactic context effects on word recognition: A developmental study. Scandinavian Journal of Psychology, 35, 27-37.

HyöNÄ, J., \& VAINIO, S. (2001). Reading morphologically complex clause structures in Finnish. European Journal of Cognitive Psychology, 13, 451-474.

HyönÄ, J., Vainio, S., \& Laine, M. (2002). A morphological effect obtains for isolated words but not for words in sentence context. European Journal of Cognitive Psychology, 14, 417-433.

KaAn, E., Harris, A., Gibson, E., \& Holcomb, P. (2000). The P600 as an index of syntactic integration difficulty. Language \& Cognitive Processes, 15, 159-201.

Laine, M., \& Virtanen, P. (1999). WordMill, Lexical Search Program [Computer software]. Turku, Finland: University of Turku.

LaUdanna, A., \& Burani, C. (1995). Distributional properties of derivational affixes: Implications for processing. In L. B. Feldman (Ed.), Morphological aspects of language processing (pp. 345-364). Hillsdale, NJ: Erlbaum.

Lukatela, G., Kostić, A., Todorović, D., Carello, C., \& Turvey, M. T. (1987). Type and number of violations and the grammatical congruency effect in lexical decision. Psychological Research, 49, 37-43.

MacWhinney, B., \& Pleh, C. (1997). Double agreement: Role identification in Hungarian. Language \& Cognitive Processes, 12, 67-102.

Marslen-Wilson, W., Tyler, L. K., WaKsler, R., \& Older, L. (1994). Morphology and meaning in the English mental lexicon. Psychological Review, 101, 3-33.

Nicol, J. L., Forster, K., \& Veres, C. (1997). Subject-verb agreement 
processes in comprehension. Journal of Memory \& Language, 36, 569-587.

NiKolOVA, R., \& JAREMA, G. (2002). Interaction of morphological structure and prefix transparency in the processing of Bulgarian aspectual verb forms. Brain \& Language, 81, 649-665.

Osterhout, L., \& Mobley, L. A. (1995). Event-related brain potentials elicited by failure to agree. Journal of Memory \& Language, 34, 739-773.

Pearlmutter, N. J., Garnsey, S. M., \& Bock, K. (1999). Agreement processes in sentence comprehension. Journal of Memory \& Language, 41, 427-456.

RAYNER, K., \& DUfFy, S. A. (1986). Lexical complexity and fixation times in reading: Effects of word frequency, verb complexity, and lexical ambiguity. Memory \& Cognition, 14, 191-201.

SCHREUDER, R., \& BAAYEN, R. H. (1995). Modeling morphological processing. In L. B. Feldman (Ed.), Morphological aspects of language processing (pp. 131-154). Hillsdale, NJ: Erlbaum.

Schriefers, H., Friederici, A. D., \& Rose, U. (1998). Context effects in visual word recognition: Lexical relatedness and syntactic context. Memory \& Cognition, 26, 1292-1303.

Sereno, S. C., Rayner, K., \& Posner, M. I. (1998). Establishing a time-line of word recognition: Evidence from eye movements and event-related potentials. NeuroReport, 9, 2195-2200.

Sulkala, H., \& Karjalainen, M. (1992). Finnish. New York: Routledge.

TAFT, M. (1994). Interactive-activation as a framework for understanding morphological processing. Language \& Cognitive Processes, 9 , 271-294.

Thornton, R., \& MacDonald, M. C. (2003). Plausibility and grammatical agreement. Journal of Memory \& Language, 48, 740-759.
Vainio, S., Hyönä, J., \& Pajunen, A. (2003). Facilitatory and inhibitory effects of grammatical agreement: Evidence from readers' eye fixation patterns. Brain \& Language, 85, 197-202.

VIlKuna, M. (1989). Free word order in Finnish: Its syntax and discourse functions. Helsinki: SKS.

Virtanen, P., \& Pajunen, A. (2000). ContextMill [Computer software]. Turku, Finland: University of Turku.

\section{NOTES}

1. Inessive can also express a part-whole relationship (e.g., auton takaosassa oli kolarin jäljilttä paha lommo = "in the back part of the car there was a bad dent due to a crash").

2 . The covariate analyses by participants were done as follows. We first computed a regression analysis separately for the experimental conditions in which the logarithmic frequency of the word $n-1$ was used to predict the fixation time on the target word. We then used the individual beta coefficients to compute the individual corrected reading times for each condition by using the following formula: original fixation time - (beta coefficient $\times$ original fixation time). Finally, we computed an ANOVA (Experiment 1) or a $t$ test (Experiment 3 ) on these corrected fixation times. For the item analysis, we were able to compute a standard covariate ANOVA.

3. The results are calculated for the trials in which word $n+1$ was fixated immediately after fixation of the target noun. The percentage of such trials was $88.2 \%$ in Experiment 1, 89.4\% in Experiment 2, and $87.4 \%$ in Experiment 3.

(Manuscript received October 6, 2005; revision accepted for publication August 5, 2007.) 